\title{
Youmna Charara, Roman et politique. Approche sérielle et intertextuelle du roman des Lumieres
}

\section{Regina Bochenek-Franczakowa}

\section{(2) OpenEdition}

1 Journals

\section{Édition électronique}

URL : http://journals.openedition.org/studifrancesi/30277

DOI : $10.4000 /$ studifrancesi.30277

ISSN : 2421-5856

Éditeur

Rosenberg \& Sellier

\section{Édition imprimée}

Date de publication : 1 avril 2006

Pagination : 153-154

ISSN : 0039-2944

\section{Référence électronique}

Regina Bochenek-Franczakowa, «Youmna Charara, Roman et politique. Approche sérielle et

intertextuelle du roman des Lumieres », Studi Francesi [En ligne], 148 (XLX | I) | 2006, mis en ligne le 30 novembre 2015, consulté le 21 avril 2021. URL : http://journals.openedition.org/studifrancesi/30277 ; DOI : https://doi.org/10.4000/studifrancesi.30277

Ce document a été généré automatiquement le 21 avril 2021.

\section{(c) $($ ) $\odot$}

Studi Francesi è distribuita con Licenza Creative Commons Attribuzione - Non commerciale - Non opere derivate 4.0 Internazionale. 


\title{
Youmna Charara, Roman et politique. Approche sérielle et intertextuelle du roman des Lumieres
}

\author{
Regina Bochenek-Franczakowa
}

\section{RÉFÉRENCE}

YOUMNA CHARARA, Roman et politique. Approche sérielle et intertextuelle du roman des Lumieres, Paris, Honoré Champion («Moralia», 12), 2004, pp. 506.

1 L'auteur de l'ouvrage se propose de dégager «l'expression d'une conscience ou d'un sentiment politique» dans le roman des Lumières (p. 10). En somme, le travail «se fonde sur la solidarité» établie par l'auteur entre des formes romanesques et des représentations politiques: du roman à thèse, où la relation politique idéologique est évidente et centrale, jusqu'aux «romans de la vie privée» qui mettent en scène des liens sociaux empruntés aux discours philosophiques contemporains (p. 17). L'approche sérielle et intertextuelle, appliquée à un vaste corpus de romans, environ 40 œuvres, sert à contextualiser celles-ci aussi bien à l'intérieur de récits comparables («la série») que dans les rapports d'échange avec des écrits non romanesques, en premier lieu, philosophiques et historiques. Dans la première partie de l'ouvrage («Morale et politique»), l'A. étudie le roman à thèse, qui comprend ici le roman d'éducation du prince, l'utopie narrative, enfin, certains romans philosophiques militants ou engagés. Dans les romans d'éducation du prince, l'A. a dégagé les mouvements dialectiques: d'un côté, les invariants tels que les séquences sur l'éducation du prince et le récit de la guerre, de l'autre, l'évolution des réécritures des Aventures de Télémaque qui aboutissent au roman anti-pédagogique et anti-politique. Quant au roman utopique, l'A. décèle que, sous la pression du contexte idéologique, la forme de l'utopie se modifie: à part le mélange des genres et l'hybridation thématique, il note l'apparition des formes 
curieuses de contre-utopies. L'analyse du «roman colonial», «américain» ou «africain», se révèle également intéressante et instructive.

Dans la deuxième partie du livre («Société et politique»), la problématique est organisée autour de deux axes: le roman historique, d'abord, que l'A. a le mérite d'étudier en rapport avec l'historiographie contemporaine où s'affrontent deux discours distincts, absolutiste et nobiliaire. Le deuxième axe est centré sur l'«individu et la politique». Le roman que l'A. désigne comme «biographique», est ici analysé dans ses modèles libertin, bourgeois, aventurier, chevaleresque (héroïque) avec sa variante parodique, enfin, républicain. Un des intérêts majeurs de ce chapitre est encore l'étude de textes inconnus, à savoir les récits de la vie militaire et de la guerre.

Dans la troisième partie de l'ouvrage («La Politique des sexes»), l'A. se penche sur d'autres «séries» de romans de la vie privée: le roman du mariage et celui du libertinage. La relecture des chefs-d'œuvre tels que Les Lettres persanes, La Nouvelle Héloïse, Clarissa Harlowe ou Les Liaisons dangereuses à la lumière des écrits philosophiques et politiques des penseurs des Lumières s'est avérée être une approche des plus intéressantes et réussies. La "guerre des sexes» entre les personnages, considérée comme une métaphore, un «équivalent réduit de la guerre civile» (p. 355), confère au topos du mariage et du libertinage une charge de sens politique importante. Le sérail des Lettres persanes comme l'image d'un état despotique; la famille comme premier modèle des sociétés politiques, dans La Nouvelle Héloïs; la conquête qui se politise, le conquérant libertin prenant les traits du «tyran», dans le roman libertin - voilà quelques - uns des thèmes des interprétations ingénieuses contenues dans cette partie de l'ouvrage.

4 L'ouvrage d'Y. Charara propose une lecture fructueuse et enrichissante des romans des Lumières, démontrant la présence et le rôle d'un «dialogue littéraire» intense entre les récits de fiction et les textes contemporains de philosophie et d'histoire. Dans cette optique, qui joint l'approche synchronique à celle diachronique, l'évolution du roman se montre sous un aspect révélateur pour la destinée ultérieure du genre: aux approches de la Révolution, le roman des Lumières, qui «a été spectateur de la vie politique», se voudra «à la fin du siècle, acteur de l'histoire politique» (p. 446). La voie vers le roman réaliste du $19^{\mathrm{e}}$ siècle est tracée. 